\title{
EL TRATAMIENTO DEL MOVIMIENTO OBRERO EN LOS MANUALES DE HISTORIA DEL MUNDO CONTEMPORÁNEO
}

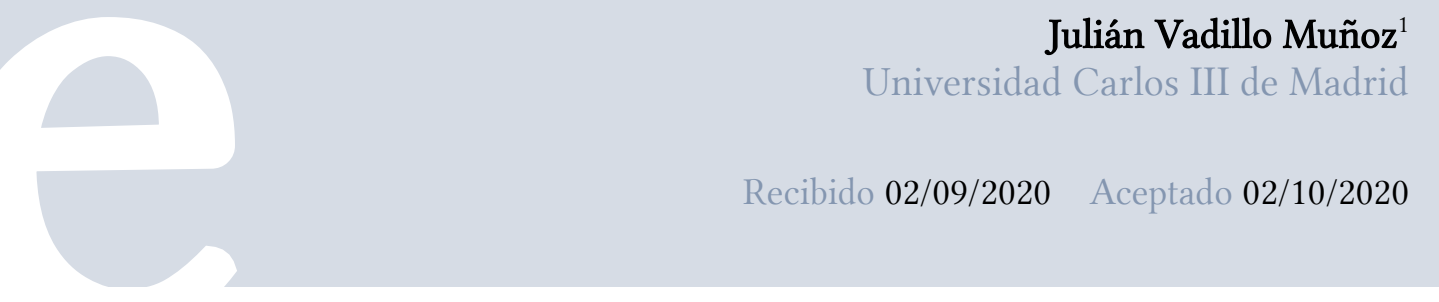

Z Los grados de educación media y el estudio del Bachillerato son fundamentales para entender determinados conceptos que van a perdurar a lo largo de tu trayectoria vital. En el caso de la historia es evidente si el sujeto no se va a dedicar al estudio de esta en los niveles superiores. Por eso, la forma de trasmisión de los contenidos es fundamental para que nos hagamos una idea de la importancia de la historia. Uno de esos contenidos en la historia del mundo contemporáneo es la importancia del movimiento obrero en el siglo XIX, en las respuestas que se dieron al desarrollo de la sociedad industrial y de corte capitalista. El objetivo de este artículo es analizar, a través de distintos manuales de los últimos años, el tratamiento que se ha dado a ese aspecto de la historia, y si existe conexión entre los contenidos ofrecidos y las investigaciones sobre la temática.

$\forall$ Secondary education and the study of the Bachillerato is fundamental to understanding certain concepts that will last throughout your life. In the case of history, it is evident if the subject is not going to dedicate himself to the study of history in the higher levels. For this reason, the way in which the contents are transmitted is fundamental in order for us to get an idea of the importance of history. One of those contents in the history of the contemporary world is the importance of the labour movement in the 19th century, in the responses to the development of the industrial and capitalist society. The objective of this article is to analyse, through different manuals of the last years, the treatment given to this aspect of history, and if there is a connection between the contents offered and the research on the subject..

DOI

https://doi.org/10.15366/didacticas2020.23.006

PALABRAS CLAVE

Movimiento obrero; Anarquismo; Marxismo; Sindicalismo; Internacionales. als. 


\section{INTRODUCCIÓN}

No cabe ninguna duda que el tratamiento de la educación en nuestro país ha cambiado en las últimas décadas, adaptando los distintos manuales de texto a las circunstancias y las leyes que se han aprobado en el marco del sistema democrático. El tratamiento de la Historia Universal y del movimiento obrero en este sentido han cambiado mucho, desde los manuales que se utilizaron en nuestro país en tiempos pretéritos para analizar la historia autóctona o la Europea y Universal. Así nos lo atestigua párrafos como los siguientes. Este primero corresponde al análisis que se hacía en un manual alrededor de la Revolución de 1848 en Francia:

Por esto se esforzaron los miembros radicales del gobierno provisional, Ledru-Rollin y Luis Blanc, en impedir las elecciones y en afianzar su poder mediante concesiones al proletariado parisién. (...) Las orientaciones socialistas se introdujeron con los 'Talleres Nacionales' de París. En estos se consumían muchos millones para alimentar a miles de obreros holgazanes (Sternfeld, 1935, pps. 252-253).

Otro ejemplo lo tenemos, en el tratamiento de un acontecimiento clave para el obrerismo como la Comuna de París de 1871:

El 18 de marzo sobrevino en París una terrible revolución, la Commune, cuyas raíces estaban en una conjuración socialista internacional. Sus focos se encontraban en los barrios obreros, en los cuales ya durante el sitio habían ocurrido desordenes. Esta revolución tuvo aterrorizada a la capital con sus crueldades durante dos meses. (...) el 28 de mayo pudo sofocarse la revolución, después de sangrientas luchas en las calles, no sin que los revolucionarios hubiesen incendiado antes magníficas construcciones como las Tullerías (Sternfeld, 1935, p. 271).

Estos textos, con sus visiones apocalípticas, fueron utilizados durante muchos años en diversos manuales de historia universal. El movimiento obrero era visto o bien como una maldición divina, siempre relacionado con la violencia y desde luego, como un grave problema de orden público. Unas ideas, que se mantuvieron durante mucho tiempo y que, incluso, en algunos casos se siguen asimilando, aunque no la visión de aquel manual de Sternfeld.

Aunque las visiones son distintas y adaptadas, lo cierto es que hay que hacer una valoración de cómo se aborda la Historia del Mundo Contemporáneo en los libros de texto. Aquí nos vamos a aproximar a como han trabajado los libros de texto de Primero de Bachillero un tema central para entender las consecuencias de la revolución industrial, las respuestas al modelo económico del momento y a lo que supuso las alternativas sociales durante el último tercio del siglo XIX y casi todo el siglo XX: el movimiento obrero.

Lo que se va a hacer es un análisis de los temas que los manuales dedican a este periodo del siglo XIX, a los orígenes del obrerismo y las primeras respuestas, así como a las organizaciones de las grandes organizaciones internacionales y las tendencias revolucio- 
narias más importantes: el marxismo y el anarquismo. Y se hace con un muestro de manuales, desde el más antiguo que data de 1996 hasta el moderno que hemos seleccionado de 2015. Veinte años de diferencia entre uno y otro, donde cambiaron los planes de estudios, pues el modelo BUP-COU, impartía la Historia del Mundo Contemporánea en el Curso de Orientación Universitaria (COU) y en la actualidad, en la modalidad ESO-Bachillerato, esta materia se imparte en Primero de Bachillerato. En el primer caso eran los contenidos que se evaluaban en la Selectividad como medio de acceso a la Universidad.

Las razones que motivan este análisis son variadas, si bien se pueden entender en una falta de conexión entre las investigaciones que se hacen en el espacio académico y el mundo de secundaria. Un déficit que se dan por ambas partes, pues existe una laguna de secundaria hacia la investigación universitaria y un abandono de la Universidad hacía los centros de enseñanzas medias. Aquí lo hemos reducido al tratamiento de un aspecto concreto en manuales de Bachillerato, pero se podía hacer extensivo a otros campos. Evidentemente, no se dan en todos los casos y dependiendo del manual y del autor de este, el tratamiento del tema es abordado de una u otra manera.

En este artículo no nos fijamos tanto en esos cambios de planes de estudio sino en los contenidos, independientemente de las Comunidades Autónomas, que son las que tienen la competencia en materia educativa, y del curso en cuestión.

Un tema de interés que se podría hacer extensible a otros acontecimientos de la edad contemporánea como la Revolución Francesa, la Revolución rusa o las guerras mundiales.

\section{EL MOVIMIENTO OBRERO EN LA HISTORIA RECIENTE}

No cabe duda, que tras la caída del Muro de Berlín en 1989 y la desaparición de la URSS en 1991, la historia social, y con ella la historia del movimiento obrero, se sumergió en una profunda crisis de la que tardaría en salir. No porque los historiadores que la trabajasen fuese defensores acérrimos del sistema soviético, sino porque el trabajo y tratamiento de estas cuestiones automáticamente se vinculaba a ello y comenzó y emerger nuevos planteamientos de la historia que hizo poco atractivo el estudio del obrerismo.

Además, tanto en España como en el resto de Europa comenzó a aparecer una nueva historiografía del obrerismo que intentaba dar un trazado de investigación distinto al que se había ofrecido hasta el momento o no tan sujeto a un esquema del marxismo más clásico:

Mas allá de la historia del movimiento obrero, la historia obrera se englobó en el marco más general de una historia social preocupada por aprehender los diferentes aspectos del mundo obrero y las mutaciones más recientes de las sociedades industriales (Ceamanos, 2004, p. 148). 
Dejando a un lado que no toda la historia del movimiento obrero se trabajaba de la misma manera, pues no era lo mismo las diferentes escuelas del bloque socialista y las escuelas del mundo occidental, donde incluso en ambos casos había variantes y distintas visiones, incluso las mejores referencias partían de escuelas que diferían entre sí. La escuela francesa con personajes como Jean Maitron o Annie Kriegel era sensiblemente distintas a la británica de historiadores como E.P. Thompson o Eric J. Hobsbawm. En España, se tendría el caso característico de Manuel Tuñón de Lara.

Ese concepto de historia más clásico, por utilizar una denominación, fue variando con el paso de los años. En Francia aparecieron personajes como Alain Cottereau, que analizó las condiciones de trabajo y la salud de los trabajadores, acotando los espacios de estudio del obrerismo y alejándolo lo puramente organizativo, cuestión que siguió siendo trabajada por otros como Jacques Droz o Michel Winock. En España aparece una nueva historiografía del obrerismo vinculada a profesores como Manuel Pérez Ledesma o José Álvarez Junco que comenzaron a trabajar la historia del movimiento obrero, ya fuese socialista o anarquista, con implicaciones sociológicas y antropológicas (Pérez Ledesma y Álvarez Junco, 1982; Pérez Ledesma, 1987; Álvarez Junco, 1991).

Ello dio paso a una nueva generación de historiadores que se fueron formando en criterios abiertos y que, en muchas ocasiones, rescataban la reconstrucción organizativa pero la llevaba a los espacios micro o locales, aportando grandes cuestiones a la historia del movimiento obrero. Sin parar a citar trabajos concretos aquí podemos ubicar las obras de historiadores como Julio Aróstegui, Javier Paniagua, Julián Casanova, Pere Gabriel, Santos Juliá, Alejandro Díez Torre, Santiago Castillo, Rafael Cruz, José Luis Gutiérrez Molina, etc., por referirnos a un marco español. Muchos de ellos volvieron a trabajar las organizaciones, ya fuesen socialistas, comunistas o anarquistas, en su amplio espectro pero introduciendo novedades y trabajando fuentes que eran inaccesibles en los años de la dictadura franquista y que se fueron abriendo poco a poco.

A ellos, se fueron uniendo con el paso del tiempo, y ya en la década de 2000 historiadores de nuevo cuño que fueron confeccionando una nueva historiografía. Aquí cabría Fernando Hernández Sánchez, Chris Ealham, Francisco Sánchez Pérez, Juan Pablo Calero Delso, Dolors Marín Silvestre, Sandra Souto Kustrín, Carlos Gil Andrés, Roberto Ceamanos Llorens, José Luis Ledesma, etc., siguiendo con los ejemplos de la reciente historiografía española. Muchos de ellos analizan movimiento en toda su extensión o bien aspectos concretos de algunas ideologías y organizaciones.

No es una cuestión de analizar cada una de las obras de estos autores, cada una en su campo y si ha tenido reflejo en los libros de textos que estudia el alumnado en el Instituto, sino mostrar que la historia del obrerismo ha sido trabajada, ha ido superando lugares comunes y avanzado en el campo historiográfico y que en muchas ocasiones, esas cuestiones no se han visto reflejadas en los libros de textos. 


\section{EL MOVIMIENTO OBRERO EN LOS MANUALES DE HISTORIA DEL MUNDO CONTEMPORÁNEO}

Una de las variaciones que se ha dado a lo largo del tiempo y de los cambios legislativos en materia de enseñanza secundaria ha sido el estudio de la Historia del Mundo Contemporáneo. Si bien, con el modelo BUP-COU, esta parte de la historia se abordaba en parte de $1^{\circ}$ de BUP y en COU, con la reforma educativa que llevó a la ESO y Bachillerato, la historia universal contemporánea se aborda en parte del temario de $4^{\circ}$ de la ESO y en Primero de Bachillerato.

Además, tanto en España como en el resto de Europa comenzó a aparecer una nueva historiografía del obrerismo que intentaba dar un trazado de investigación distinto al que se había ofrecido hasta el momento o no tan sujeto a un esquema del marxismo más clásico:

Mas allá de la historia del movimiento obrero, la historia obrera se englobó en el marco más general de una historia social preocupada por aprehender los diferentes aspectos del mundo obrero y las mutaciones más recientes de las sociedades industriales (Ceamanos, 2004, p. 148).

Dejando a un lado que no toda la historia del movimiento obrero se trabajaba de la misma manera, pues no era lo mismo las diferentes escuelas del bloque socialista y las escuelas del mundo occidental, donde incluso en ambos casos había variantes y distintas visiones, incluso las mejores referencias partían de escuelas que diferían entre sí. La escuela francesa con personajes como Jean Maitron o Annie Kriegel era sensiblemente distintas a la británica de historiadores como E.P. Thompson o Eric J. Hobsbawm. En España, se tendría el caso característico de Manuel Tuñón de Lara.

Ese concepto de historia más clásico, por utilizar una denominación, fue variando con el paso de los años. En Francia aparecieron personajes como Alain Cottereau, que analizó las condiciones de trabajo y la salud de los trabajadores, acotando los espacios de estudio del obrerismo y alejándolo lo puramente organizativo, cuestión que siguió siendo trabajada por otros como Jacques Droz o Michel Winock. En España aparece una nueva historiografía del obrerismo vinculada a profesores como Manuel Pérez Ledesma o José Álvarez Junco que comenzaron a trabajar la historia del movimiento obrero, ya fuese socialista o anarquista, con implicaciones sociológicas y antropológicas (Pérez Ledesma y Álvarez Junco, 1982; Pérez Ledesma, 1987; Álvarez Junco, 1991).

Ello dio paso a una nueva generación de historiadores que se fueron formando en criterios abiertos y que, en muchas ocasiones, rescataban la reconstrucción organizativa pero la llevaba a los espacios micro o locales, aportando grandes cuestiones a la historia del movimiento obrero. Sin parar a citar trabajos concretos aquí podemos ubicar las obras de historiadores como Julio Aróstegui, Javier Paniagua, Julián Casanova, Pere Gabriel, Santos Juliá, Alejandro Díez Torre, Santiago Castillo, Rafael Cruz, José Luis Gutié- 
rrez Molina, etc., por referirnos a un marco español. Muchos de ellos volvieron a trabajar las organizaciones, ya fuesen socialistas, comunistas o anarquistas, en su amplio espectro pero introduciendo novedades y trabajando fuentes que eran inaccesibles en los años de la dictadura franquista y que se fueron abriendo poco a poco.

A ellos, se fueron uniendo con el paso del tiempo, y ya en la década de 2000 historiadores de nuevo cuño que fueron confeccionando una nueva historiografía. Aquí cabría Fernando Hernández Sánchez, Chris Ealham, Francisco Sánchez Pérez, Juan Pablo Calero Delso, Dolors Marín Silvestre, Sandra Souto Kustrín, Carlos Gil Andrés, Roberto Ceamanos Llorens, José Luis Ledesma, etc., siguiendo con los ejemplos de la reciente historiografía española. Muchos de ellos analizan movimiento en toda su extensión o bien aspectos concretos de algunas ideologías y organizaciones.

No es una cuestión de analizar cada una de las obras de estos autores, cada una en su campo y si ha tenido reflejo en los libros de textos que estudia el alumnado en el Instituto, sino mostrar que la historia del obrerismo ha sido trabajada, ha ido superando lugares comunes y avanzado en el campo historiográfico y que en muchas ocasiones, esas cuestiones no se han visto reflejadas en los libros de textos.

\section{EL MOVIMIENTO OBRERO EN LOS MANUALES DE HISTORIA DEL MUNDO CONTEMPORÁNEO}

Una de las variaciones que se ha dado a lo largo del tiempo y de los cambios legislativos en materia de enseñanza secundaria ha sido el estudio de la Historia del Mundo Contemporáneo. Si bien, con el modelo BUP-COU, esta parte de la historia se abordaba en parte de $1^{\circ}$ de BUP y en COU, con la reforma educativa que llevó a la ESO y Bachillerato, la historia universal contemporánea se aborda en parte del temario de $4^{\circ}$ de la ESO y en Primero de Bachillerato.

La estructura que han seguido estos manuales es muy similar a la hora de abordar el movimiento obrero, a pesar de los cambios de legislación. Temas como los orígenes y concepto del proletariado, desarrollo del obrerismo industrial y las respuestas al mismo, desde el ludismo al socialismo utópico hasta llegar a la conformación de los grandes bloques ideológicos y organizativos del obrerismo: el marxismo, el anarquismo y las Internacionales. Algunos de estos manuales, también abordan la respuesta que la Iglesia dio a finales del siglo XIX con su doctrina social y la expansión de las ideas de la Rerum Novarum de León XIII. En la mayoría de las ocasiones estas explicaciones amplias en el cuerpo de texto están acompañada de algunos cuadros explicativos o textos de época para poder reforzar el conocimiento y la ubicación del tema tratado.

En la parte de mundo contemporáneo se ha seleccionado los siguientes manuales. El primero de los libros que hemos analizado corresponde al coordinado por el profesor Julio Montero y editado por Tempo en el año 1996 con el título Historia del mundo con- 
temporáneo. Era uno de los manuales que se utilizaba para la preparación de la selectividad en COU (Curso de Orientación Universitaria). Un libro completo que, incluso, aparecía referenciado en algunas bibliografías de la Licenciatura de Historia, como manual de apoyo para la preparación de las asignaturas de mundo contemporáneo. En sus páginas colaboraron profesores de enseñanzas medias y universitarias, destacando de entre estos últimos a especialistas de reconocido prestigio como Carlos Hermida, Javier Cervera Gil o el propio Julio Montero. El capítulo concerniente al movimiento obrero es obra de $\mathrm{Pe}$ dro Gago, como complemento al capítulo sobre el desarrollo del industrialismo de Antonio González Pacheco y completando lo dicho por María Antonia Paz en el capítulo donde se incluye las primeras respuestas al modelo económico capitalista. Otro es el de María Candelas González y Elena Cabezalí publicado por Akal en 2002. El tercero es el libro colectivo publicado por Anaya en 2008, donde escriben reconocidos contemporaneistas como Carlos Forcadell. El de Oxford de 2011 se ha seleccionado por haber sido escrito por uno de los especialistas actuales en historia del movimiento obrero: el profesor de la Universidad Carlos III de Madrid Francisco Sánchez Pérez. Por último, el manual que Vicens-Vives publicó en 2015 tiene como uno de sus principales autores a otro de los especialistas en movimiento obrero como fue el catedrático de la Universidad Complutense de Madrid, Julio Aróstegui Sánchez. Todos los manuales se titulan de la misma forma: Historia del Mundo Contemporáneo.

Vamos a hacer un seguimiento a los mismos desde apartados algunos de los principales aspectos que van a abordando en sus páginas.

\section{Las respuestas y los orígenes del movimiento obrero}

Una cosa en la que coinciden todos los manuales es en hablar, en primer lugar, de las respuestas que se dieron a la sociedad industrial, partiendo de principios como el socialismo utópico o movimientos como el ludismo. Aunque bien es cierto, que el manual dirigido por Montero en 1996 tiene más estructura de un libro de carácter universitario a los que ahora se tiene en los centros de enseñanzas medias.

Esos orígenes en el manual de Montero son abordados en el capítulo 2, escrito por María Antonia Paz, y donde la autora analiza los fundamentos ideológicos de la revolución liberal, se incluyen las primeras respuestas al desarrollo del modelo capitalista, y aquí, junto al liberalismo y la democracia, la autora introduce los primeros socialismos:

Nacen de los principios de la Ilustración y buscan un nuevo orden basado en la armonía social. Se caracterizan por tender a implantar un sistema de organización colectiva de producción apoyado, no en la fuerza, sino en la libre voluntad de los hombres, tanto obreros como empresarios (Montero Díaz, 1996, p. 32).

Aunque de una forma muy sintética y sin abordar aspectos más profundos, se explican las respuestas de Robert Owen, con el desarrollo del cooperativismo y de proyectos 
como New Harmony (por ejemplo no cita las medidas laborales que Owen introdujo en otro proyecto como New Lanark, cuestión de enorme importancia), las de Saint-Simon y Fourier, pero sin citar los falansterios, la de Louis Blanc y sus Talleres Nacionales o la de Pierre Joseph Proudhon, que acertadamente coloca como iniciador del anarquismo al intentar sustituir el Estado por una federación. No profundiza el manual en esas respuestas, y se deja en el tintero algunas cuestiones de importancia, sobre todo el impacto que el owenismo tendría sobre las Trade Unions, o de Proudhon como un socialista que intentó dar una respuesta científica a la economía del momento (Álvarez Layna, 2015; De Cabo, 1995). Tampoco se desarrolla como funcionaban los Talleres Nacionales en la época de la Revolución de 1848 y en que quedaba las propuestas de Louis Blanc al respecto. Otros socialismos, como los de Cabet o Auguste Blanqui, ni aparecen.

La cuestión es que los límites de estos nunca tienen un establecimiento único ni unificado en los manuales, y cada autor incluye a una serie de personajes que complementan a los clásicos de Saint-Simon, Fourier u Owen. El manual de María Candelas González y Elena Cabezalí tiene la peculiaridad de que no solo aborda los orígenes ideológicos sino que se centra en movimientos como los luditas. Para las autoras, este movimiento no solo era destruir la máquina sino que servía como medida de presión para conseguir mejoras a la clase obrera (González González y Cabezalí García, 2002, p. 32). Además, es muy interesante porque sitúan el desarrollo del movimiento obrero en la oleada democratizadora del siglo XIX y aunque no se detiene en exceso en ello, habla de las fronteras difusas que existían entre distintos movimientos políticos renovadores y revolucionarios, algo que si está muy en relación con los estudios del obrerismo en otros ámbitos de los niveles educativos superiores:

Los socialistas de los primeros decenios del siglo XIX compartían muchas ideas con los republicanos radicales, pero tenían además una ideología propia que se ha dado en llamar socialismo utópico, un movimiento que quería transformar la sociedad en beneficio de los más pobres, que pretendían acabar con las injusticias y el deterioro al que la industria y el liberalismo habían dado lugar (González González y Cabezalí García, 2002, p. 33).

Sin embargo, esos primeros socialismos o socialismo utópico, es algo que todos manuales abordan de una forma u otra. El manual de Forcadell, con buen criterio, lo denomina "socialismo premarxista" pues ciertamente la categorización de "utópico" proviene de la contraposición que el marxismo le hace al socialismo por denominar el suyo como "científico". Hilando más fino establece las tendencias socialistas (Owen Saint-Simon y Fourier), las preanarquistas (aparece Godwin, Stirner y Proudhon), las precomunistas (Babeuf y Cabet). Son citas, que en ocasiones quedan confusas por no entrar, aunque sea de forma somera, a analizar cada una de las propuestas establecidas.

En el caso de Francisco Sánchez Pérez este primer periodo solo es citado, pues su análisis más consistente se produce con el movimiento obrero organizado como organismo político y de masas. El manual de Aróstegui sí que se detiene a analizar cada uno de esos 
primeros socialismos, analizando el vanguardismo e igualitarismo de Babeuf y Blanqui, el falansterio de Fourier, la Icaria de Cabet, el cooperativismo de Owen. Es quizá el más completa en este sentido.

Y habría que destacar una cosa de estos primeros socialismos. En la mayoría de los casos quedan esquemáticos y a veces desdibujados. Solo el manual de Aróstegui tiene una mayor consistencia. Y este último manual hay que destacar una cosa. No cita a Saint-Simon como un originario socialista, pues en realidad el pensador francés no era socialista sino un liberal avanzado. Sería su escuela, el sansimonismo, la que adoptaría el ideal so cialista como respuesta, y aquí se puede ver una explicación de las razones por las que se obvia. Sin embargo, estos primeros socialismos quedan más en el aire, y se incluye o no a personajes que o bien son de entre épocas (Blanc o Blanqui que responderían a un paso intermedio entre los primeros socialismos y las grandes organizaciones de masas) o bien fundamentan el movimiento obrero organizado (Proudhon) y otros no pasan de ser filósofos (como Stirner). Y es que el genérico de "utópico" motiva que su tratamiento sea menor a pesar de las importancias de sus ideas.

\section{El marxismo}

La influencia que ha tenido el marxismo a lo largo de la historia contemporánea y su trascendencia en la política y la sociedad merece un tratamiento exhaustivo y serio del rol que jugó en su nacimiento y expansión en el entorno natural que se originó: el movimiento obrero. Esto le convierte en un tema clave de estudio en la historia del mundo contemporáneo, por su implicación en periodos posteriores como la Revolución rusa o la política de bloques tras la Segunda Guerra Mundial. Partiendo de una buena historia comparativa y de los debates en interior del marxismo, se pueden y debe entender las distintas corrientes, movimientos y procesos que se fueron originando a lo largo de la historia contemporánea. Pero no solo eso, pues el marxismo fue también una herramienta de análisis de la historia que generó distintas escuelas y corrientes de interpretación durante el mismo periodo (Droz, 1979; Beer, 1973; Winock, 1992).

En este aspecto hay una enorme diferencia entre el modelo de abordar el marxismo por los distintos manuales.

Para Pedro Gago, autor del capítulo dedicado al movimiento obrero en el manual de Julio Montero, el marxismo en una concepción doctrinal que une diversas corrientes e influencias, desde Hegel hasta los avances científicos del siglo XIX; pasando por el socialismo francés y la economía clásica británica. El componente marxista lo va a sintetizar en cuatro puntos básicos: a) Materialismo histórico, con la influencia de Hegel; b) La lucha de clases que el autor define como una interpretación simple de la historia; c) La contradicción del sistema capitalista, referenciando obras como El Capital; d) Dictadura del proletariado, definida por el autor como el paso por el cual la humanidad saldría de la prehistoria para entrar en la historia (Montero Díaz, 1996, p. 122). En líneas generales, se 
le aplica al marxismo una enorme carga negativa sin entrar a analizar su importancia en el desarrollo del movimiento obrero a partir de la segunda mitad del siglo XIX o la influencia del marxismo en sociedades revolucionarias como las ligas (ejemplo de la Liga de los Comunistas).

González y Cabezalí se apoyan más en textos como el Manifiesto Comunista para ir exponiendo de forma sintética la teoría marxista de análisis social en un entorno de sociedad de clases. Aquí si van a engarzar la importancia del marxismo en el nacimiento de la Internacional, aunque establecen con muy bien criterio que esa AIT, nacida en Londres en 1864, era la convergencia de multitud de tendencias y no solo la marxista, que en muchos otros manuales y en la historia en general se sobredimensiona. No varía mucho, en este sentido, el manual de Forcadell donde se centra un poco más que los anteriores en las figuras de Marx y Engels y en la importancia que tuvieron para el desarrollo de los partidos socialistas en el mundo.

Pero los dos mejores manuales para la explicación del marxismo, lo tenemos con los ejemplos de Sánchez Pérez y Aróstegui. El manual de Oxford, a pesar de la brevedad de su tratamiento, es muy completo. Partiendo de una miniintroducción de Marx y Engels, citando el Manifiesto Comunista, posteriormente en un cuadro se especifican las aportaciones del marxismo (Sánchez Pérez, 2011, p. 93): el motor de la historia es la lucha de clases, las contradicciones del sistema capitalista llevarán a su colapso y autodestrucción y el trabajo de la clase obrera para la conquista del poder político. En el caso del manual de Vicens Vives, el marxismo es trabajado a la perfección en cuatro consistentes párrafos donde se desgrana lo más significativo de la ideología marxista (Arósttegui y otros, 2012, p. 72).

Dentro del marxismo, podríamos incluir el concepto de la socialdemocracia y la formación de los partidos socialistas por el mundo. La desaparición de la Primera Internacional significó una resignificación de muchas cuestiones en el marxismo político.

Para analizar la socialdemocracia, el libro de Montero parte del congreso de unificación de Gotha. También destaca nombres de personajes que luego no volverán a aparecer en otros manuales como el de Ferdinand Lasalle. Sin embargo, este manual reduce las aportaciones de la socialdemocracia al propio Lasalle y Bernstein, olvidando cualquier referencia a los debates que se dieron en el SPD con personajes como Karl Kautsky o Rosa Luxemburg. Además, define la socialdemocracia de la siguiente manera:

La democracia es un instrumento fundamental del progreso social así como un medio de lucha por el socialismo. Es, además la forma de realización del socialismo. La democracia social, síntesis de la democracia propiamente dicha y del liberalismo, constituye el único régimen que puede conseguir la extracción de todo lo que ha tenido de valioso los diferentes sistemas culturales y políticos precedentes (Montero Díaz, 1996, p. 123). 
El hecho de no abordar una cuestión tan importante como el debate del socialismo alemán o francés, rompe un poco la dinámica explicativa de debates posteriores como la posición del socialismo ante la Primera Guerra Mundial y la Revolución rusa de 1917.

El libro de González y Cabezalí no aborda esta cuestión, aunque si lo hace el de Forcadell en Anaya, al poner al SPD como el partido paradigmático entre los socialistas del momento y citar los casos de Gran Bretaña con el nacimiento a inicios del siglo XX del Partido Laborista o el de España con el nacimiento del PSOE en 1879. Sin embargo, Francia con los debates entre Guesde (y Lafargue) con Jaurès ni siquiera son citados.

El de Francisco Sánchez Pérez, aunque sintético, sí que cita el nacimiento de los principales partidos socialistas en el mundo: SPD en Alemania, SFIO en Francia, Partido Laborista en Gran Bretaña y el PSOE en España.

Una vez más, el de Vicens Vives vuelve a ser el más completo en este aspecto. En él se distingue muy bien en el interior del SPD la corriente revisionista de Bernstein, la de Kautsky y la revolucionaria de Rosa Luxemburg y Karl Liebknecht. Muy bien explicadas y sintetizadas para alumnos del nivel de Primero de Bachillerato. Igualmente, en este punto también se cita la importancia de Lenin dentro del socialismo en las corrientes más maximalistas y con buen criterio se citan los casos de Francia y Rusia, diferenciando entre la posición de la "ortodoxia revolucionaria" (Aróstegui y otros, 2012, p. 78) frente a la posición de Jean Jaurès, tendente a acuerdos con el resto de las fuerzas obreras y progresistas y cuyo trabajo y tendencia desembocaría en la fundación de la SFIO. Un pequeño espacio lo dedican al PSOE y al socialismo austriaco de Otto Bauer, lo que hace que este manual sea uno de los más completo y coherentes en este sentido.

\section{El anarquismo}

Sin embargo, como norma que se cumple en casi todos los manuales, es el anarquismo el movimiento peor abordado (Paniagua, 2012; Woodcock, 1979; Joll, 1978; Horowitz, 1990). El manual de Julio Montero establece una conclusión común al anarquismo que es su oposición al proceso de industrialización afirmando los siguiente:

Todos sus partidarios vienen a coincidir en el rechazo, expreso o no, del proceso de industrialización y pretenden establecer una sociedad cooperativa de individuos de base agraria (Montero Diaz, 1996, p. 122).

Una afirmación sin base histórica, pues el anarquismo y los anarquistas no se oponen al proceso de industrialización y de avance sino al modelo que lo lidera (coincidiendo en ello con el marxismo). Además, la afirmación está fundamentada en la dicotomía y argumento binario de que el marxismo hablaba al proletariado industrial y el anarquismo al mundo agrario y atrasado. Junto a esta valoración del anarquismo, realiza una división de su doctrina en distintas tendencias que reduce a sindicalismo, pacifismo y terrorismo 
indiscriminado, con lo que la violencia se sitúa en este caso como eje central de la doctrina. Junto a ello cita a autores como William Godwin o Max Stirner, a los que sitúa en la base individualista (en el caso de Godwin no se sostiene), León Tolstoi, al que cataloga de moralista, y a Piotr Kropotkin, Errico Malatesta, Jean Grave y Mijaíl Bakunin a los que denomina comunistas. En el caso de Bakunin es un error situarlo como comunista, pues era un colectivista. El comunismo en el anarquismo aparecerá posteriormente de forma extendida en base a los primeros autores citados. Por último, en el juicio de valor sobre el anarquismo, establece que su doctrina tiene "(...) escasa coherencia y falta de sistematización” (Montero Díaz, 1996, p. 122).

Y es que el eje de la violencia como parte inherente al movimiento anarquista o la falta de organización, son lugares comunes que no solo se repiten en los manuales de Bachillerato, sino que incluso alcanza a alguno de los manuales más utilizado en el ámbito universitario. Para González y Cabezalí, el anarquismo queda desdibujado, no encajando bien con ninguna concepción obrera ni con una participación coherente en la Primera Internacional. Aunque bien es cierto, que cita bien a las distintas escuelas o interpretaciones del anarquismo en el siglo XIX (mutualismo de Proudhon, colectivismo de Bakunin y comunismo de Kropotkin), no deja de citar la violencia como eje trasversal y, al mismo tiempo, ubicar el triunfo del anarquismo a los lugares de escasa industrialización (Rusia, España, Italia, etc.). Incluso el manual de Anaya habla muy poco del anarquismo, tan solo vinculando sus ramas a la organización sindical o la actuación terrorista y obviando cualquier tipo de referencia al federalismo, la Alianza de la Democracia Socialista, la diversidad organizativa, etc. El planteamiento que este manual ofrece del anarquismo es completamente confuso.

El manual de Oxford de Sánchez Pérez si se acerca de forma más consistente al anarquismo si bien afirma que el movimiento se separó del socialismo cuando éste se hizo marxista (Sánchez Pérez, 2011, p. 93), cuando en realidad el anarquismo nunca dejó de ser socialista y se reclamó como tal, con los apellidos de antiautoritario o bakuninista. Sin embargo, Sánchez Pérez es un buen conocedor de la historia del obrerismo y si marca muy bien la dualidad organizativa que los anarquistas tuvieron (grupos específicos y sindicato), aunque no deja de aparecer la dicotomía industrialización y falta de ella para hablar de las zonas de afianzamiento del anarquismo:

La influencia anarquista fue notable en países de industrialización atrasada y democracia débil o inexistente (como España, Italia y Rusia). En su radicalismo, algunos anarquistas llegaron incluso a cometer atentados contra jefes de Estado y políticos (Sánchez Pérez, 2011, p. 93).

Los lugares comunes tampoco son ajenos al manual donde participa Aróstegui, sobre todo en la cuestión de la violencia. Aun así, el anarquismo es trabajado correctamente, aunque de forma mucho más laxa que el marxismo. El manual ubica bien y resumen de forma correcta la doctrina anarquista, colocando a Proudhon y Bakunin como sus principales representantes. Aunque el manual si tiene un especial interés en marcar una infe- 
rioridad doctrinal del anarquismo respecto al marxismo, no resta ningún tipo de importancia a lo que supuso en el desarrollo del movimiento obrero internacional. Además, el manual analiza el movimiento anarquista tras la desaparición de la AIT y enlaza con la importancia del Congreso de Londres de 1881. Aunque este manual, incluso en contra de las visiones de libros específicos sobre la materia, no vincula a personajes como Kropothin o Malatesta en esta corriente. El eje fuerte del anarquismo en este libro de texto se comprueba en la visión que se da entre las tendencias de carácter sindical, de las que hablaremos más adelante, y la violencia. Resaltando en este caso la importancia que para el anarquismo tuvo movimientos como el antimilitarismo, el anticlericalismo o la visión internacionalista.

\section{Las Internacionales}

El siglo XIX fue testigo del nacimiento de dos internacionales obreras: la Asociación Internacional de los Trabajadores (AIT) o Primera Internacional, nacida en 1864 en Londres y que comenzó a tener una importancia en el continente europeo a partir de 1866. Y la Segunda Internacional en 1889, más estructurada hacía los partidos políticos y que contó con la exclusión del movimiento anarquista (Kriegel, 1977; Freymond, 1973, Eckhardt, 2017).

Es un tema nada baladí para la compresión del movimiento obrero, pues la fundación de estas entidades supranacionales marcó el acervo internacionalista de este movimiento $\mathrm{y}$, al mismo tiempo, la importancia de los debates que se dieron en el interior del movimiento obrero entre las principales escuelas en el último tercio del siglo XIX.

Sin embargo, sobre la proyección e importancia de esas internacionales, no todos los manuales lo abordan de la misma manera, y a veces quedan de una forma muy esquemática que impiden ver la verdadera importancia que tuvieron. Si bien el manual coordinado por Montero sí que sitúa bien los orígenes de la Primera Internacional en la influencia de las ideas de Proudhon, no marca bien la evolución de esta y afirma que los sindicalistas británicos abandonaron la Internacional por su oposición a la Comuna de París. Y aunque la fractura de la Internacional la sitúa en el Congreso de La Haya de septiembre de 1872 (sin citar el congreso de Saint-Imier), se afirma que Bakunin fundó, una vez expulsado de la Internacional la Alianza de la Democracia Socialista (Montero Díaz, 1996, p. 125), organización que en realidad había sido fundada mucho antes y disuelta por el propio Bakunin en 1869 para convertirla en una sección de la AIT en Ginebra.

De la Segunda Internacional lo que destaca es su fundación en el año 1889 (aunque contiene una errata) y la diversidad de tendencias que se dieron en un interior, dividiendo el periodo entre 1889-1905, destacando las figura de Millerand como socialista que participó en un consejo de ministros en Francia, y un segundo momento entre 19051914, donde se habla del revisionismo de Bernstein, el modelo de Luxemburgo-Liebkne- 
cht y el modelo bolchevique de Lenin, en un reduccionismo que desfigura los debates profundos que tuvieron en la Segunda Internacional.

El manual de González y Cabezalí, aborda la Internacional tras explicar el marxismo y antes de hablar del anarquismo, lo que hace que muchas cuestiones queden difusas. Aunque con muy buen criterio se establece una diversidad de tendencias en la fundación de la Internacional, las aportaciones de Proudhon no se citan, al no haber sido aun explicado el propio anarquismo. Aunque se marca la necesidad del organismo por parte de los trabajadores, no hay mucha explicación en cuanto a su funcionamiento. Se habla de una implantación rápida, no se remarca las zonas de influencia y une de forma irremediable los sucesos de París de 1871 con el propio programa de la AIT, cuando en realidad la Comuna fue un acontecimiento mucho más profundo. Sin entrar a fondo en las diferencias de tendencias en el interior de la AIT, se marca la ruptura de esta en 1872 por las posiciones discordantes entre Marx y Bakunin. La Segunda Internacional de 1889 no es analizada.

El manual de Anaya hace un recorrido explicando el marxismo, la AIT y el anarquismo prácticamente en un bloque, donde se analiza el origen de la AIT y la preminencia que el manual le da a Marx en la fundación y desarrollo de esta, cuando en realidad el pensador alemán no fue tan determinante en los orígenes y sí a posteriori en los debates. Y aunque se habla de distintas tendencias en el interior del organismo, no se establece un cambio gradual de las mismas ni la basculación entre ellas, importante para entender el devenir de la Internacional. Sin mucha solución de continuidad, tras una explicación muy somera del anarquismo, se pasa rápidamente a hablar de la Comuna de París y de la ruptura de la Internacional, que sitúa en el Congreso de La Haya de septiembre de 1872. Aquí hay una cuestión que repite otros manuales, y es que esa ruptura parece que se dio en un congreso con todas las partes presentes, cuando en realidad el Congreso de La Haya fue una excepcionalidad donde no todos los anarquistas asistieron. Por último coloca el fin de la AIT en 1876, obviando que los anarquistas mantuvieron una estructura internacional heredera tras el congreso de Saint-Imier y que duró mucho más en el tiempo.

De la Segunda Internacional lo único que destaca es que fue un intento de coordinación de todos los partidos socialistas del mundo, excluyendo a los anarquistas, y hablando de acontecimientos de calado internacional como el 8 de marzo o el 1 de mayo, pero sin hablar del origen de estos.

Aunque el manual de Sánchez Pérez es muy sintético en lo que se refiere al desarrollo de las Internacionales y no se aborda con profundidad los debates de estas, si introduce una novedad de enorme valor. Aparejado a estos movimientos supranacionales van apareciendo una serie de movimientos sociales que van a surgir en la época como el derecho de la mujer por su emancipación, centrado en EEUU y Gran Bretaña, y la lucha del pueblo judío y el nacimiento del sionismo (Sánchez Pérez, 2011, p. 96), muy vinculado en ocasiones al socialismo aunque sin entrar en el manual en partidos clave como el Bund. Y estas cuestiones de carácter internacional son muy importantes en un contexto de edu- 
cativo de secundaria, lo que indica que el autor está al día de las corrientes historiográficas más modernas que introducen las variables de género u otros aspectos de carácter internacional importante, no solo ceñido al ámbito puramente obrero.

El libro de Aróstegui aborda el nacimiento de la Primera Internacional de forma muy coherente, hablando de la fundación, de los debates doctrinales entre Marx y Bakunin, etc. Pero en la desaparición de la Internacional también pone su final en 1876, cuando Marx disuelve su facción en Nueva York obviando, en este caso, las estructuras que seguían manteniendo los anarquistas.

En lo que respecta a la Segunda Internacional, este manual es el más completo de todos, pues le dedica dos páginas y tres epígrafes a esta organización supranacional. En primer lugar hace una comparativa con la desaparecida AIT, dando a esta nueva Internacional un toque más homogéneo, pues lo que se coordina son partidos socialistas. Y se habla de la aprobación de cuestiones de calado como la celebración del Primero de Mayo a partir de 1890 en base a los sucesos de Chicago de 1886. Por otra parte, aborda los debates de la Internacional, donde por una parte establece lo que se discutió alrededor de la guerra, haciendo referencia a los congresos de Copenhague en 1910 y de Basilea en 1912 para marcar la contradicción entre esos acuerdos y las disposiciones de las distintas secciones en las vísperas de la Primera Guerra Mundial. Y aquí, en un nuevo epígrafe, se marca la diferencia de facciones y grupos dentro de la propia Internacional, entre los pacifistas, los patriotas y los revolucionarios que querían convertir la guerra en un efecto transformador social, anticipando la importancia de los bolcheviques (Aróstegui y oros, 2012 , p. 81) y la determinación que estos debates tendrían para el nacimiento de la Komintern o Tercera Internacional.

\section{La Comuna de París}

Pocos acontecimientos en la historia del movimiento obrero han sido tan importantes como la Comuna de París. Un proceso abierto en plena Guerra franco-prusiana y que pasa a ser el mejor exponente del control por parte de los trabajadores de una ciudad. Con un concepto federalista de la organización política, en París convergieron en su reestructuración y defensa distintas escuelas políticas de la izquierda y del obrerismo pujante que desarrollaron una experiencia que pasaría al imaginario colectivo de los revolucionarios posteriores.

Si bien en España no ha habido muchas investigaciones en específico sobre la Comuna de París, destacando en este caso la obra del profesor Roberto Ceamanos (Ceamanos, 2014), conocemos muchas traducciones de libros franceses o, incluso, nos podemos acercar al idioma de nuestro país vecino. En los libros y manuales sobre la historia del movimiento obrero en España sí que se ha trabajado el impacto que tuvo el acontecimiento en nuestro país, pero no se han hecho estudios exhaustivos sobre el proceso parisino desde 
las universidades españolas. Esto quizá es una razón por la que el proceso tampoco es especialmente tratado en los libros de texto de Bachillerato.

Aunque todos la citan, vamos a centrarnos en como trata el acontecimiento dos manuales. El coordinado por Julio Montero y el que participa Julio Aróstegui, para ver también como en perspectiva se puede trabajar el acontecimiento con casi 20 años de diferencia. También porque ambos textos son los que más se centran en el suceso o le dedican más espacio.

Pedro Gago, en el manual de Julio Montero, utiliza el último epígrafe del libro para hablar de la Comuna de París. Comienza hablando de los grupos mayoritarios en el acontecimiento, que eran los proudhonianos y los blanquistas, dinamizadores del obrerismo francés en los años precedentes. Sin embargo, el autor carga en el epígrafe contra la visión de Marx sobre la Comuna a la que considera distorsionada. Aun así, el autor dice que solo se adoptó una medida socialista durante la Comuna de París:

Sin embargo, solo adoptó una medida socialista: elaborar planes para formar cooperativas de producción integrados por trabajadores despedidos (Montero Díaz, 1996, p. 126).

Aquí el autor no se para a comprobar cuales fueron las medidas reales de la Comuna ni se aborda los distintos debates, los grupos etc. Junto a toda una serie de medidas como las reducciones de jornadas laborales, control de los trabajadores de los medios de producción, democracia directa en los distintos barrios, etc., tampoco se aborda los efectos de la Comuna a nivel general en Francia ni la represión que liquidó la experiencia en la llamada Semana Sangrienta de finales de mayo de 1871.

Muy distintos es el enfoque que se dio en el manual de Julio Aróstegui, donde la Comuna de París no queda desapercibida sino que se le dedica un epígrafe completo, definiendo su estructura como la plasmación de la República democrática y social (Aróstegui y otros, 2012, p. 75), en un contexto de guerra que perjudicó su desarrollo. Además de definir bien para el nivel de estudios lo que fue la Comuna de París, la refuerza con cuadros explicativos de personajes como Louise Michel, una de las principales dirigentes del acontecimiento y que sería, después, representante del anarquismo francés. También aporta datos específicos sobre la represión, con cuadros numéricos de la misma. Un tratamiento muy acertado.

\section{La doctrina social de la Iglesia}

Aunque menos trabajado en los niveles educativos medios, en muchas ocasiones los manuales completan el panorama del movimiento obrero con la aportación realizada en la conocida como "doctrina social de la Iglesia" y de la implicación del mundo eclesiástico en las visiones del liberalismo, el capitalismo y las respuestas socialistas a finales del siglo XIX. No es que la Iglesia organice y desarrolle un movimiento obrero, pero dio una 
respuesta, mayoritariamente en la década de 1890, a la expansión del industrialismo, del capitalismo y del mismo socialismo que comenzaba a tener mucha influencia entre la base obrera y campesina.

No podemos decir que esa doctrina social de la Iglesia fuese un movimiento obrero, básicamente porque negaba y renunciaba a la lucha de clases y lo que pretendía era una conciliación entre capital y trabajo de carácter asistencial y caritativo, dando una cara más suave a un modelo que estaba generando enormes desigualdades sociales. Además, muchos grupos alrededor de la doctrina social de la Iglesia acabaron por organizar sindicatos de clase que defendían los intereses de los trabajadores, que creaban organismos asistenciales pero que también se enfrentaban a los poderosos sindicatos obreros socialistas y anarquistas.

Es importante, por lo tanto, establecer las características de este fenómeno, que en algunos países llegaron a tener influencia y que dio origen a distintos movimientos dentro de una estructura rígida y ortodoxa como la Iglesia católica. Aun así no dejaron de ser minoritarios y testimoniales en muchos lugares. Pero los manuales que se han analizado abordan de distinto modo este fenómeno, dándole mayor o menor importancia, incluso omitiendo en algunos de ellos su propia existencia.

De todos ellos el que más sorprende es el texto de Pedro Gago, dentro del manual de Julio Montero. Lo es porque el primer aspecto que analiza el autor en el tema dedicado al movimiento obrero es precisamente este, el del catolicismo y la doctrina sociales de la Iglesia. Aunque sobredimensiona su importancia, el tratamiento no deja de ser original ya que habla de una organización obrera católica, resaltando la importancia que tuvo la encíclica de León XIII Rerum Novarum y destaca figuras que ningún otro manual va a abordar: el Marqués de La Tour du Pin, Frederik Le Play o Wilhem Emmanuel Ketteler. Estableciendo ese punto de crítica al capitalismo y al comunismo, el manual no deja de emitir un juicio de valor sobre la importancia de esta doctrina social:

El comunismo es un sistema cerrado que ofrece una visión integral del mundo, de la historia, y de la ética, fundado en el ateísmo militante (Montero Díaz, 1996, p. 120).

Sin entrar a valorar si es conveniente o no utilizar el término comunismo en genérico, lo cierto es que el manual sobredimensiona un movimiento que no fue tan determinante en el ámbito obrero (excepto en algunos espacios).

Curiosamente, ninguno de los otros manuales analizados trata este aspecto, aunque sí aparece en numerosos manuales de Historia de España de Segundo de Bachillerato, teniendo en cuenta que uno de los lugares donde el catolicismo social tuvo influencia fue en España. 


\section{Otros aspectos por destacar}

Aunque las cuestiones abordadas anteriormente son trasversales a casi todos los manuales, algunos de ellos abordan cuestiones de interés que luego no se repiten en otros, lo que en muchas ocasiones genera un vacío o una falta de continuidad de los contenidos tratados en este aspecto. Aquí se van a destacar algunas peculiaridades de "esas otras cosas" que se analizan.

Un ejemplo lo tenemos con el texto de Pedro Gago, en el manual de Julio Montero, cuando dentro del desarrollo del movimiento obrero analiza lo que denomina "sindicalismo apolítico". Una curiosa forma de denominar a lo que en realidad intenta explicar, que es el sindicalismo revolucionario francés, aunque con algunas peculiaridades. Si bien el manual habla de la estrategia de acción directa y de huelga, divide el sindicalismo en "posibilista", liderado por Millerand, "anarcosindicalista" que lo define como que "pretendía apoyar al obrero en todos los aspectos de la vida" (Montero Díaz, 1996, p. 124) y "sindicalismo revolucionario" definido como aquel que tiene "una participación violenta contra el Estado". De una forma muy confusa, el autor confunde términos. El anarcosindicalismo sería un fenómeno muy posterior a lo que el autor pretende establecer y, al mismo tiempo, desconoce la evolución del sindicalismo revolucionario. En este aspecto no cita ni la Federación de Bolsas de Trabajo o la CGT en Francia, base de ese sindicalis mo. Y tampoco aparecen personajes clave para la evolución de este como Fernand Pelloutier o Émile Pouget. Por el contrario, sí que cita a George Sorel, pero le adjudica cuestiones que no son propias u originales de este pensador francés, como la estrategia de huelga general. Un modelo de lucha obrera que estaba presente en la mentalidad y organización societaria francesa a través de las aportaciones de Tortelier, Pelloutier, Pouget o Yvetot, personajes muchos más influyentes en ese sentido que Sorel.

El movimiento sindical, por su parte, es analizado por el manual de Cabezalí y González como antecedentes a los movimientos obreros internacionales, enganchándolo con el cartismo. En parte es un argumento correcto, pues el sindicalismo británico de esa época estaba en plena ebullición, pero su origen es anterior, pues en el contexto británico habría que enmarcarlo en las consecuencias de la represión del ludismo y la conformación de un sindicalismo de carácter antiestatal que combatió en la década de 1820 el parlamentarismo de algunos reformistas (Beer, 1973, p. 270). Posteriormente, el cartismo y el desarrollo de tendencias como el owenismo lograron articular el tradeunionismo como una de las bases fundamentales del movimiento obrero británico.

En el manual de Prats y Forcadell de la editorial Anaya, el sindicalismo es tratado de forma muy sucinta, vinculado como término a Francia pero sin dejar claro si se refiere al sindicalismo revolucionario de finales del siglo XIX o a modelos de sociedades obreras anteriores.

El manual de Sánchez Pérez si hace una interesante aproximación al modelo sindical, como elemento de desarrollo del movimiento obrero, resaltado los instrumentos de los 
que se valió como la acción directa y la huelga. En este sentido, Sánchez Pérez, con buen criterio, pone la fuerza del sindicalismo en las estrategias que los libertarios adquirieron, aunque pone ejemplos basados en España con el importante desarrollo que tuvieron entidades como la UGT y la CNT. También como la huelga se convirtió en un instrumento de lucha científica frente a los antiguos motines de subsistencia, lo que hace que el movimiento obrero post Primera Internacional adquiriese un carácter más extensivo. Este manual introduce un cuadro explicativo de la evolución de los sindicatos desde sociedades de socorros mutuos a sociedades de resistencia, muy esclarecedor para cualquier alumno (Sánchez Perez, 2011, p. 96).

El libro de Julio Aróstegui también analiza de forma pormenorizada el sindicalismo y su origen. Lejos de otros manuales, este incide sobre el desarrollo del sindicalismo en el primer tercio del siglo XIX en Inglaterra. Esas sociedades obreras que van surgiendo en la década de 1820, que recogen la tradición de lucha obrera legada por el ludismo pero le dotaron de una organización, tiene un fuerte componente antiestatal. Son uniones locales, tal como establece el manual. Y como esa idea sindical va creciendo a lo largo del tiempo, esas sociedades se fueron haciendo más grandes y más fuerte. Es importante estas cuestiones, porque la base sobre la que creció el movimiento obrero británico fue la base sindical. Owen la perfeccionó y el propio Partido Laborista nació en base a los sindicatos. De hecho, esto les sirve para enganchar con el siguiente epígrafe, que no es otro que la Carta del Pueblo o el cartismo, muy influyente desde 1838, que nació como fruto de la experiencia de la Great Trade Union y de recientemente fundada Working Men's Association. Se condensan muy bien las peticiones de la Carta del Pueblo: derecho al sufragio y la representación, derechos sociales y políticos, laborales, etc., con toda una estrategia de movilización (Aróstegui y otros, 2012, pps. 68-69).

Posteriormente volverá a incidir sobre la vía sindical, tras la ruptura de la Primera Internacional, tanto por parte del sector marxista, que desarrollaría sus entidades sindicales ligadas al desarrollo de los partidos obreros (Aróstegui y otros, 2012, p. 77), o de la rama anarquista con el modelo del sindicalismo revolucionario que sería paradigma en Francia y en España con la CGT y la CNT respectivamente (Aróstegui y otros, 2012, p. 78).

Como último dato a destacar, tan solo el libro de Julio Aróstegui analiza de forma un poco más profunda el origen de fechas simbólicas para el obrerismo como el Primero de Mayo, vinculado a la represión contra los trabajadores de Chicago en 1886 por la petición de las ocho horas de trabajo.

\section{CONCLUSIÓN}

Los libros y manuales analizados a lo largo del presente trabajo trabajan de forma muy distinta la historia del movimiento obrero, adaptada para alumnos de Bachillerato y con los respectivos cambios introducidos en os últimos veinte años a raíz del cambio, de forma permanente, de las legislaciones educativas. Aunque la ley educativa es estatal ha pe- 
culiaridades autonómicas que habría que tener en cuenta y que no han sido objetivo del presente trabajo. En realidad, los manuales analizados corresponden todos a estudios concernientes a la Comunidad de Madrid, aunque se podría hacer extensivo a otros espacios autonómicos.

Lo cierto, es que la totalidad de los manuales analizados coinciden, con el paso del tiempo, en los contenidos, si bien las visiones, conclusiones o la importancia que se ofrece a la historia del movimiento obrero varía.

Se puede establecer una primera conclusión en relación con el tratamiento de los orígenes del movimiento obrero o las respuestas socialistas al desarrollo industrial, que to dos hablan sobre el denominado "socialismo utópico", si bien la profundización en cada una de sus propuestas es distinta. El primer componente de diferenciación es a quien se incluye dentro de ese grupo y la propia denominación. No son en los distintos manuales los mismos protagonistas, pues varían. Aunque Owen y Fourier aparece prácticamente en todos, la inclusión de otros como Louis Blanc, Auguste Blanqui, Étienne Cabet, etc., genera polémica. Si algo ha aclarado la historiografía sobre el socialismo, es que esas respuestas van a pasando por distintas etapas. Que la terminología de "utópico" responde más bien a una contra visión del socialismo "científico" marxista y que estas respuestas sirven para nutrir en el futuro respuestas más cerradas en organizaciones más contundentes.

Aunque en algunos manuales, la visión del marxismo tiene una enorme carga peyorativa, es el anarquismo el que se lleva la peor parte al desfigurar su trayectoria organizativa y no quedar claro los límites de sus tendencias. La idea de la desorganización del anarquismo y su especial énfasis en la violencia, son aspectos muy remarcados que impiden ver cual es la verdadera dimensión de un movimiento que fue determinante en la historia de muchos países, incluido España. Esta es una carga negativa que desfigura la participación protagonista del anarquismo en muchos procesos históricos de la edad contemporánea.

Igualmente, al acercarnos a acontecimientos como la Comuna de París o los orígenes de fecha tan marcadas en el calendario obrerista como el Primero de Mayo, los manuales son escasos a la hora de analizarlo. La Comuna de París, episodio poco trabajado por la historiografía en España, salvo para ver el impacto que tuvo en las organizaciones obreras de nuestro país, tiene un manto de desconocimiento general sobre lo que supuso, su impacto, sus medidas y el imaginario colectivo que legó a la historia del movimiento obrero. Sobre el origen del Primero de Mayo, del 8 de Marzo u otras fechas de interés, casi ningún manual nos hace algo aproximativo. Es algo sencillo de explicar y que sirve para que el entorno que rodea al alumnado conozca las razones del simbolismo de determinadas fechas. 
También hay que destacar que los contenidos que se analizan tienen un amplio carácter eurocéntrico. Lugares como EEUU, el Extremo Oriente o América Latina apenas tienen espacio para ver el desarrollo del obrerismo.

Sin embargo, es cierto que hay manuales que trabajan de forma muy correcta el movimiento obrero. De los analizados hay que destacar el de la editorial Oxford escrito por el profesor Francisco Sánchez Pérez, y el de la editorial Vicens-Vives donde participa el catedrático de la UCM, hoy tristemente desaparecido, Julio Aróstegui. En caso de estos dos manuales se unen cuestiones de interés. Ambos autores han sido profesores de educación secundaria y de educación universitaria. Ambos, también, son reconocidos especialistas en la historia del movimiento obrero. Esa conexión que se da entre el ámbito de los Institutos y el universitario permite que estos profesores estuviesen al día de los novedosos trabajos sobre la historia del movimiento obrero. Hoy esos manuales, que se podían haber adaptado a las nuevas normativas, están en desuso o las editoriales han renovado sus plantillas de profesores.

La conclusión general es, que aunque hay manuales que se ajustan a una comprensión muy acertada de la historia del obrerismo, la mayoría de los casos hay una desconexión entre los estudios del movimiento obrero que se realizan en los ámbitos universitarios y los contenidos que se imparten en las aulas de secundaria y bachillerato. Esa desconexión es recíproca, pues si bien el no tratamiento de obras actuales hace que aspectos superados se repitan con el paso del tiempo, generando con ellos lugares comunes desfasados en una parte de la población, también motiva que haya una falta de interés por parte de los investigadores a como se imparten determinados contenidos en los niveles medios. Una situación que habría que superar con una mejor interconexión entre ambos espacios académicos.

\section{REFERENCIAS}

ÁLVAREZ JUNCO, J. (1991): La ideología política del anarquismo español (1868-1910), Madrid: Siglo XXI.

ÁLVAREZ LAYNA, J.R. (2015): Robert Owen. Socialista utópico, Madrid: McGraw Hill

ARÓSTEGUI, J. ET ALT. (2012): Historia del mundo contemporáneo, Barcelona: VicensVives.

BEER, M. (1973): Historia general del socialismo y de las luchas sociales, Buenos Aires: Ediciones Siglo Veinte.

CEAMANOS LLORENS, R. (2004): De la historia del movimiento obrero a la historia social. L'Actualité de l'HIstoire (1951-1960) y Le Mouvement Social (1960-2000), Zaragoza: Prensas Universitarias de Zaragoza.

CEAMANOS, R. (2014): La Comuna de París (1871), Madrid: Los Libros de la Catarata. 
DE CABO, I. (1995): Los socialistas utópicos, Barcelona: Ariel.

DROZ, J. (1979) : Historia del socialismo. De 1875 a 1918, Barcelona, Destino.

ECKHARDT, W. (2017): La Primera Internacional y la Alianza en España, Madrid: Fundación Anselmo Lorenzo.

FREYMOND, J. (1973): La Primera Internacional, Madrid: Zero ZYX.

GONZÁLEZ GONZÁLEZ, M.C. y CABEZALÍ GARCÍA, E. (2002): Historia del mundo contemporáneo, Madrid: Akal.

HOROWITZ, I.L. (1990) : Los anarquistas. La teoría. La práctica, Madrid, Alianza.

JOLL, J. (1978): Los anarquistas, Barcelona, Grijalbo.

KRIEGEL, A. (1977): Las internacionales obreras, Barcelona: Martínez Roca.

MONTERO DÍAZ, J. (1996) (Coordinación y realización): Historia del mundo contemporáneo, Madrid: Tempo.

PANIAGUA, J. (2012): Breve historia del anarquismo, Madrid: Nowtilus.

PÉREZ LEDESMA, M. (1987): El obrero consciente, Madrid: Alianza.

PÉREZ LEDESMA, M. y ÁLVAREZ JUNCO, J. (1982): "Historia del movimiento obrero ¿una segunda ruptura?” en Revista de Occidente, Madrid, 1982.

SÁNCHEZ PÉREZ, F. (2011): Historia del mundo contemporáneo, Bilbao: Oxford.

STERNFELD, R. (1935): Historia de Francia, Barcelona: Editorial Labor, Barcelona.

WINOCK, M (1992): Le socialismo en France et en Europe (XIX-XX siècle), París, Éditions du Seuil.

WOODCOCK, G. (1979): El anarquismo. Historia de las ideas y movimientos libertarios, Barcelona, Ariel. 